\title{
ECTOPIC PREGNANCY AND ITS LONG-TERM RESULTS
}

DOI: 10.36740/WLek202001127

\author{
Alla V. Boychuk, Oksana I. Khlibovska, Yuliia B. Yakymchuk \\ I.HORBACHEVSKY TERNOPIL NATIONAL MEDICAL UNIVERSITY, TERNOPIL, UKRAINE
}

\begin{abstract}
The aim: The purpose of this study was to assess the long-term outcomes of restoration of reproductive function after surgical and medical treatment of ectopic pregnancy, taking into consideration the patency of the fallopian tubes and the incidence of uterine pregnancy.

Materials and methods: A two-stage experimental approach was used to address research objectives. In the first stage, a retrospective analysis of 615 histories of patients with ectopic pregnancy has been performed. In a second stage - we examined 140 patients, which were divided into three groups, depending on the type of treatment. The first group consisted of patients with a disturbed ectopic pregnancy, who were treated with laparotomy and tubectomy. The second group included patients with exacerbated ectopic pregnancy, who were operated by laparoscopic access. Lastly, the third group comprised of women with ectopic pregnancy who were treated with methotrexate. The main source of information used for clinical and anamnestic analysis was "medical card-patient" (f. 003 / 0).

Results: The number of patients diagnosed with ectopic pregnancy increased from 2005 to 2015. In 2005 and 2006, the laparotomy operations were 86.88\% and 83.33\%, but conservative management only $13,16 \%$ and $16,67 \%$, respectively. In 2015 , the number of patients treated with methotrexate was more than half (51.35\%) compared with 2010 and 2005 increased to $16.97 \%$ and $38.19 \%$ respectively, and laparotomy operations decreased from $86.88 \%$ in year 2005 to $18.92 \%$ in year 2015 .

Conclusions: The data showed that in women who underwent medical treatment with cytostatic, the patency of the fallopian tubes was significantly better than after surgical treatment. In cases of interrupted ectopic pregnancy for which laparotomy with the removal of the motor tube was applied, infertility of tubal peritoneal genesis developed in $60 \%$ of cases, which is consistent with the existing literature. Statistical analysis of the structure of ectopic pregnancy showed that in 2005 dominated interrupted ectopic pregnancy, due to late diagnostic and hospitalisation, that led to urgent laparotomy operations rather than conservative treatment.
\end{abstract}

KEY WORDS: ectopic pregnancy, methotrexate, infertility, removal of the fallopian tube, metrosalpingography

Wiad Lek. 2020;73(1):139-144

\section{INTRODUCTION}

Ectopic pregnancy is one of the main causes of reproductive loss in women with the tubal factor being $39 \%$ ofinfertility structure. The risk forlethality fromectopic pregnanciesis 10 times higher than that of childbirth and 50 times higher than that during an artificial abortion $[1,2]$. Particularly relevant is the problem of the first ectopic pregnancy (EP), which results in $50-80 \%$ of the patients undergoing a reproductive function after its surgical treatment, and the frequency of repeated ectopic nidations is $7-17 \%[3,4]$.

According to the literature, the conservative treatment of progressing EP by methotrexate under the control of of chorionic gonadotrophin levels leads to complete degeneration of the fetal egg $[5,6]$.Operative treatment of EP by laparoscopic access in comparison with laparotomy has a number of significant advantages, such as: small invasiveness, narcotic analgesicsrefusal, faster physical, sexual and social rehabilitation, cosmetic effect, reduction of purulent-septic complications. Indications and contraindications to the operative and conservative management of progressive ectopic pregnancy remain still current $[7,8]$.

Given the evidence presented, it is necessary to develop an advanced algorithm for progressive ectopic pregnancy and a method of operative technique that will provide an opportunity for optimal endosurgical intervention in the case of interrupted ectopic pregnancy. Therefore, the purpose of thisstudywas to elucidatethe long-term outcomesof restoration of reproductive function after surgical and medical treatment of ectopic pregnancy, according to the patency of the fallopian tubes and the incidence of uterine pregnancy.

\section{THE AIM}

The purpose of this study was to assess the long-term outcomes of restoration of reproductive function after surgical and medical treatment of ectopic pregnancy, taking into consideration the patency of the fallopian tubes and the incidence of uterine pregnancy.

\section{MATERIALS AND METODS}

This research was conducted inthe gynecological department of Ternopil municipal communal hospital №2 affiliated with the Department of Obstetrics and Gynecology of I.Horbachevsky Ternopil National Medical University. The study was conducted in accordance with ethical principles of the Declaration of Helsinki, the Council of Europe Convention on Human Rights and the relevant laws of Ukraine on conducting experimental and clinical 
Table 1. Research design

\begin{tabular}{|c|c|c|}
\hline Groups of patients & subgroups & Methods of treatment \\
\hline$(n=20)$ & & tubectomy viaa laparotomy access \\
\hline \multirow{2}{*}{ II $(n=40)$} & $\| A(n=20)$ & removal of fertilized egg by laparoscopic access with preservation of the tube \\
\hline & IIB $(n=20)$ & tubecotomy vialaparoscopic access \\
\hline \multirow{4}{*}{ III $(\mathrm{n}=80)$} & III A $(n=20)$ & methotrexate \\
\hline & IIIB $(n=20)$ & $\begin{array}{l}\text { methotrexate followed by removal of fetal egg vialaparoscopic access with } \\
\text { preservation of the tube }\end{array}$ \\
\hline & IIIC $(n=20)$ & methotrexate followed by laparoscopic tubectomy \\
\hline & IIID $(n=20)$ & methotrexate followed by tubectomy via a laparotomy access \\
\hline
\end{tabular}

studies. The patients gave informed consent to participate in the study. The protocol of the study was approved by the Commission on Bioethics of I.Horbachevsky Ternopil National Medical University.

The source of information used for clinical and anamnestic analysis was «Patients' medical records» (p. 003 / o) of the patients undergoing ectopic pregnancy. Ectopic pregnancy was diagnosed as criteria for inclusion of patients in the study. The groups were selected in accordance with the aim and objectives of this study. The control group consisted of 30 women with the physiological course of pregnancy in the first trimester.At the second stage of the study, we examined 140 patients, which were divided into threegroups, depending on the type of treatment (Table 1).

The first group consisted of patients with a disturbed ectopic pregnancy who were treated with laparotomy and tubectomy. The second group included patients with exacerbated ectopic pregnancy, who were operated by laparoscopic access, and the third group - comprised of women with EP, who were treated with methotrexate in a dose of 75-100 mg intramuscularly. If there was no effect of drug treatment, ectopic pregnancy continued to develop, patients were given prompt treatment. Depending on the type of treatment, groups were randomly divided into subgroups (Table 1 ) in order to adequately assess the results of the surveys.

The inclusion criteria for using methotrexate were as follows: the diameter of the fetal egg not more than $3.5 \mathrm{~cm}$ in the area of uterine application (according to ultrasound data), and the level of $\beta$-HCG of no more than $1500 \mathrm{IU} / 1$ as determined by the ECLIA analyzer Cobas 6000 (Roche Diagnostics, Rotkreuz, Switzerland).

The laparoscopic operation was performed using instrumentsmade by "KarlStorz" firm (Germany). Theultrasound examination for the diagnosis of ectopic pregnancy was carried out transabdominally and transvaginally usingthe ultrasound device "Aloka SSD-1800" (Toshiba, Japan) with sensors from 3.5 to $10 \mathrm{MHz}$. Metrosalpingography (MSG) was performed in the radiological department and the department of vascular surgery of Ternopil communal city hospital №2 using the Siemens Axiom Artis 20 dBA_sm15724 angiograph with a digital flat-panel detec-
tor.Monitoring of the onset of pregnancy in the examined women was carried out within 6-24 months after treatment.

Statistical analysisof the datawas performed on a personal computer usingthe STATISTICA-10 software for Windows ${ }^{\oplus}-6.0$ package. Odds Ratio (OR) and its 95\% confidence interval (95\% Confidential Interval, 95\% CI) were used to identify risk factors and predict complications. The reliability of the abolition of a pair of averages was calculated using the Student and Fisher test criteria.

\section{RESULTS AND DISCUSSION}

We conducted an analysis of various methods of ectopic pregnancy treatment during 2005 -2015 under conditions of one gynecological hospital. In 2015 the absolute number of ectopic pregnancies exceeded the indicators by $49.4 \%$ in 2005, and compared to 2010 - by $28.9 \%$ (Fig. 1).

There were significant changes inthe structure of treatment methods from 2005 to 2015, as shown in Fig 2.

In years 2005 and 2006, the share of laparotomy operations was $86.88 \%$ and $83.33 \%$, while medical treatment was only $13.16 \%$ and $16.67 \%$, respectively (Fig. 2). In 2015 , the number of patients treated with methotrexate was more than a half or $51.35 \%$, which in comparison with years 2010 and 2005 increased by $16.97 \%$ and $38.19 \%$ respectively, whereas laparotomy operations decreased by $86.88 \%$ in 2005 to $18.92 \%$ in 2015 ; laparoscopic access was dominantover laparotomic access in 2015, almost twice compared to year 2005 (29.73\% and $18.92 \%$, respectively).

Furthermore, it was found that EP is most common atthe age of 26-30. The average age of patients was (25.29 $\pm 1.75)$ years (Fig. 3$)$, and in the control group - (23.5 \pm 0.62 ) years. EPdiagnosis was established on the basis of clinical, ultrasound and laboratory methods in $65 \%$ of the surveyed patients during the period of 3-4 weeks of gestation, 20\% - in 5-6 weeksof gestation, and 15\% - in the term more than 6 weeksof gestation. The diagnosis of ectopic pregnancy was established by a transabdominal ultrasound sensor in $40.4 \%$ of women, and by transvaginal sensor - in $74.1 \%$ of women.

Determination of serum $\beta$-HCG level was performed in all patients with progressive ectopic pregnancy (EP). 

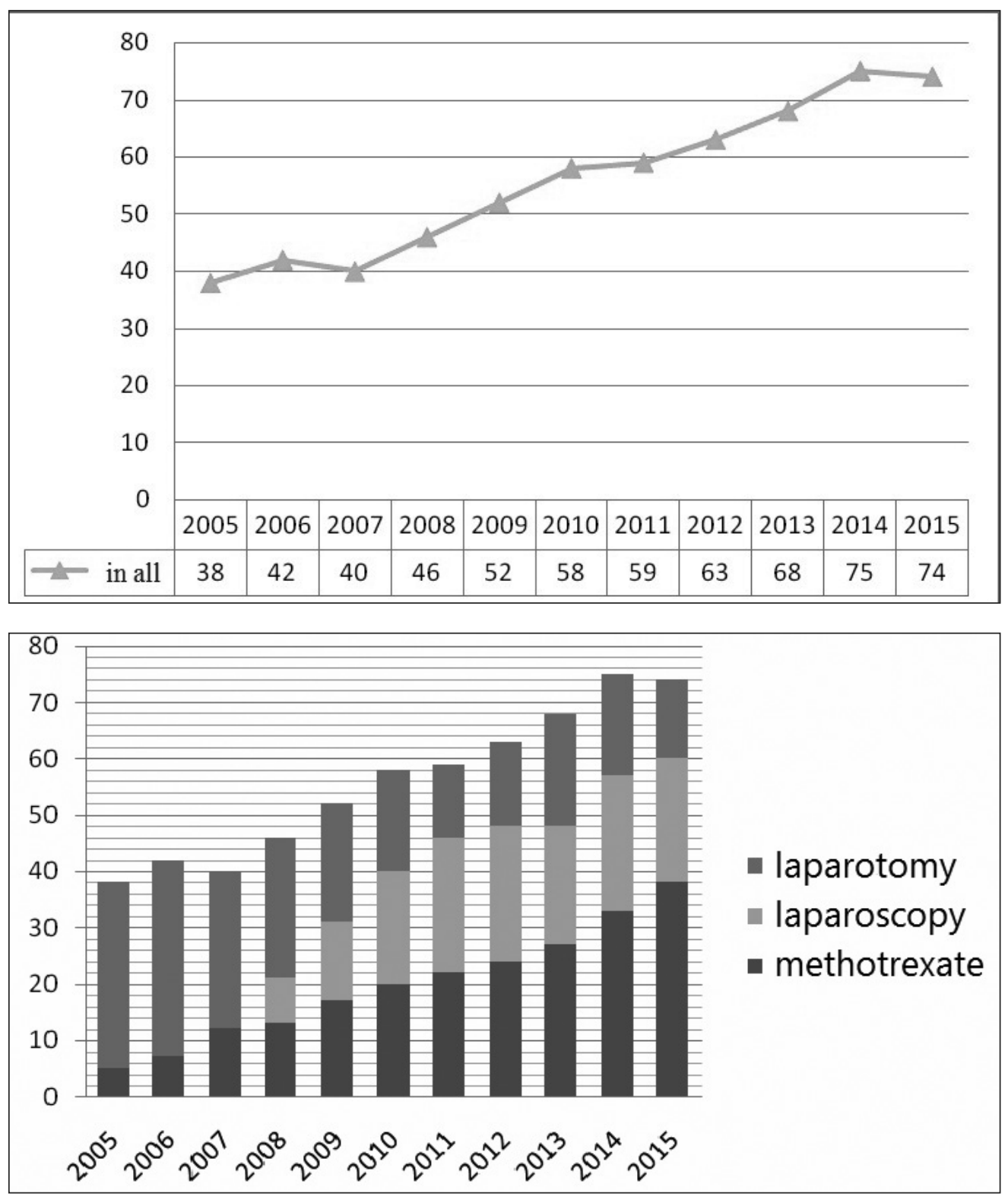

Fig. 1. Number of women with ectopic pregnancy hospitalized in the gynecological department of Ternopil municipal communal hospital №2
Fig. 2. The number of patients with ectopic pregnancy who were treated with operative (laparotomy, laparoscopic) and medication method.
At 3-4 weeks of pregnancy, the concentrationof $\beta$-HCG hormone was $476.25 \pm 11.86 \mathrm{IU} / \mathrm{L}$, and $2736.14 \pm 142.67$ IU / L in patients with ectopic pregnancy in the period of 5-6 weeks, that did not correspond to the reference value of $\beta$-HCG hormone during the physiological course of uterine pregnancy in the appropriate period.

For the purpose of differential diagnosis of ectopic pregnancy and uterine pregnancy, the growth of $\beta$-HCG was studied in the early stages. Aftera 48 -hour re-analysis, the increase in $\beta$-HCG levels was less than 1.6-fold compared to the physiological course of uterine pregnancy; a lack of growth or drop of $\beta$-HCG testified in favor of ectopic pregnancy.

Patient complaints upon arrival to the clinic were as follows: delayed menstruation $-100 \%$, pain in the lower abdomen $98.68 \%$, vertigo $-48.35 \%$, loss of consciousness $-31.29 \%$, general weakness $-78.40 \%$, and nausea $-8.30 \%$.

The analysis of gynecological history revealed thatmenstrual cycle was regular in $84.45 \%$ of women. In $78.93 \%$ of women, the cycle lasted from 21 to 28 days, it was more than 29 days in $15.76 \%$, and - 20 or less days in $5.31 \%$ of women, as presentedin Fig. 2. The duration of menstruation was on average 3-7 daysin $69.40 \%$ of women, it was up to 3 daysin $25.89 \%$ of women, and - over 1 week in $4.71 \%$ of women (Fig.4).

Menstrual dysfunction in women with ectopic pregnancy was found in $53.00 \%$ of patients and was manifested mainly by algmenorrhea in $24 \%$ of women, dysmenorrhea in $18.75 \%$, and hypertension in $9.37 \%$, which was 7.3 times that of control group ( $\mathrm{OR}=7.3$; 95\% CI: (2.51-21.25); $\mathrm{p}$ $<0.05$ ) (Fig. 5).

Among the risk factors found during the analysisof anamnestic data of patients, it was found that $40.2 \%$ of patients had early puberty $(\mathrm{OR}=4.36$; $95 \% \mathrm{CI}$ : $(1.50-12.69)$; $\mathrm{p}<0.05)$, and among different contraceptive methods, intrauterine helix prevailed in $43.4 \%$ of cases (OR $=6.9 ; 95 \%$ CI: (2.07-22.00); $\mathrm{p}<0.05)$. In $32.76 \%$ of women this pregnancy was the first, in $38.31 \%$ - the second, in $20.85 \%$ - the 


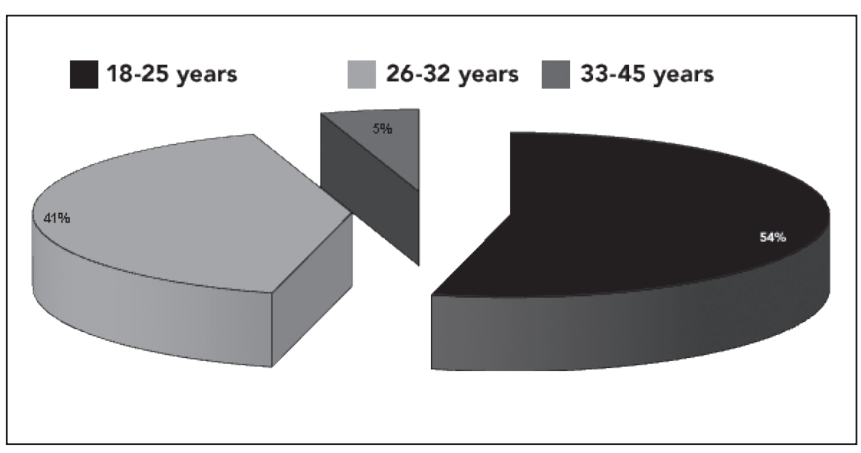

Fig. 3. Distribution of patients by age

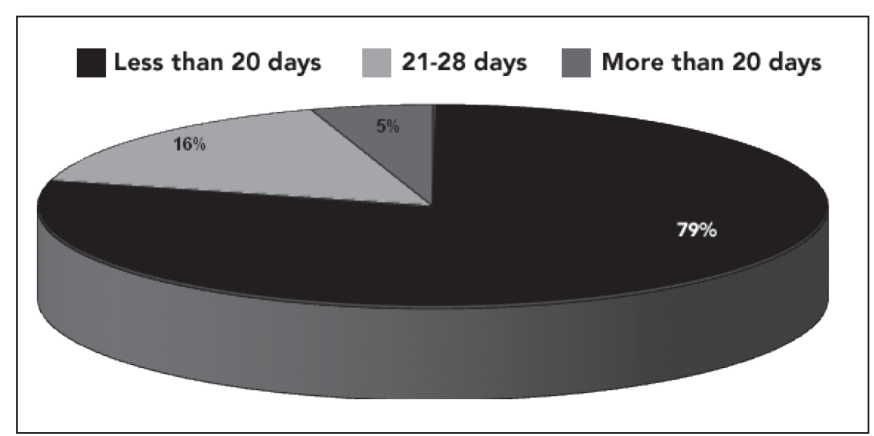

Fig. 4. Duration of the menstrual cycle

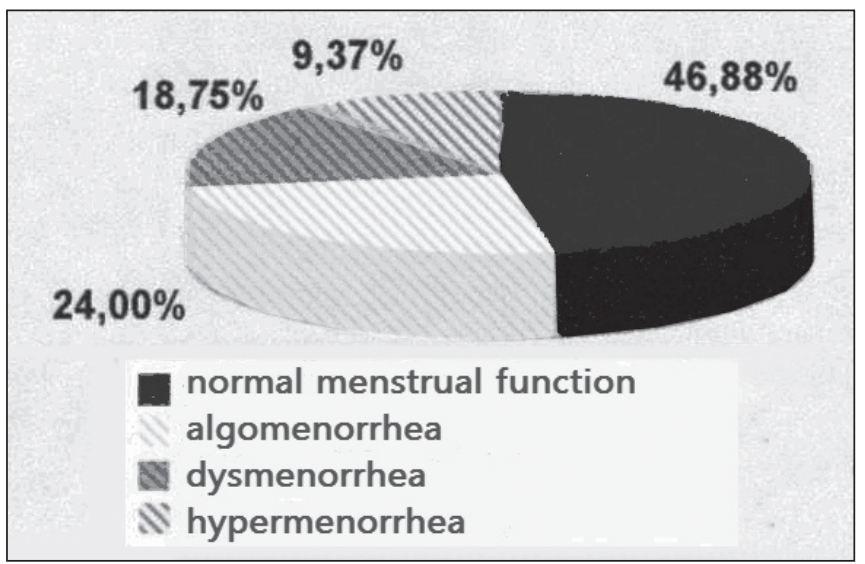

Fig. 5. Characteristics of menstrual function in the surveyed patients

third, in $8.08 \%$ - the fourth ormore. $48.74 \%$ of women had birth in history. Out of $56.25 \%$ total complications from the previous labor and the postpartum period, $28.12 \%$ of women had a subinvolution of the uterus, $15.63 \%$ - hematometry, and $12.5 \%$ - the weakness of labor. Medical abortions wereregistered in $19.2 \%$ of patients $(\mathrm{OR}=2.13$; 95\% CI: $(0.63-7.16) ; \mathrm{p}<0.05)$. Among this population, one abortion was reported in $24.4 \%$ of women, two $-8.9 \%$, and three of $1.67 \%$. Unauthorized abortions were registeredin $6.5 \%$ of the total number of women with ectopic pregnancy.

According to the anamnesis, $24.9 \%$ of the surveyed women had bad habits, namely smoking ( $\mathrm{OR}=2.98$; $95 \% \mathrm{CI}$ : (0.89-9.96); $\mathrm{p}<0.05)$. The extragenital diseases were found out in $84.4 \%$ of patients with ectopic pregnancy, pediatric infections -in 66.3\% (OR $=6.81$; 95\% CI: $(2.05-22.65)$; p $<0.05)$. Moreover, $65.6 \%$ of women with ectopic pregnancy had gynecologic diseasessuch as inflammatory diseases of the uterus and appendages, and benign tumors occurred in $40.7 \%$ of patients.

Further analysis of the data derived from 140 patients (the second stage of the study) revealed that in women of group I the restoration of menstruation after surgery occurred in 31,56 $\pm 2,09$ days, in women of group II- in 30.64 \pm 1.72 days or less than $3.54 \%$ compared togroup I, although it was not statistically significant $(p>0.05)$. Patients in the third group receiving methotrexate noted a later onset of the next menstrual period $(40.78 \pm 2.13)$, which grew by $29.2 \%(\mathrm{p}<0.05)$ compared with group I, and by group II by $33,9 \%(\mathrm{p}<0.05)$.

Table 2 shows the absolute numbers of women with passable, partially passable and obstructed uterine tubes based on the results of MSG. In group II A, where the laparoscopic operation with conservative removal of the fetal egg was performed, the number of women with the passage of the fallopian tubes was 11 or $55 \%$. In group IIIA, where methotrexate was used, this number was $17(85 \%)$, which indicates the best result in $30 \%$ of women ( $\mathrm{p}<0.05$ ).

In group IIIB (patients were administered methotrexate, and then laparoscopic intervention, conservative removal of the fetal egg was performed), women with passable fallopian tubes accounted for $70 \%$ (14 patients), which compared togroup IIIA (only methotrexate) was $15 \%$ less $(\mathrm{p}<0.05)$, but compared with group IIA (nocytostatic) it was better by $15 \%(p<0.05)$. Partially passable tubes were found in 4 patients (20\%) ofgroup IIA, 3 (15\%) patients of group IIIA, and $4(20 \%)$ patients of group IIIB, however the difference between these indicators were statistically significant $(\mathrm{p}>0.05)$. Moreover, women with obstructed uterine tubeswere $-3(15 \%)$ in group IIA and $2(10 \%)$ in group IIB, whereas the fallopian tubes obstruction was not detectedin women of group IIIA.

Patency was evaluated in women who have undergone tubectomy and hada single uterine tube that was not operated. In group I, the passable tube was in 4 women (20\%), whereas in group IIB, when performing tubectomy with laparoscopic access, the patency of the single fallopian tube was diagnosed in 12 women (60\%), which increased by $40 \%$ compared to the laparotomic method ( $\mathrm{p}<0.05)$. Following the use of methotrexate and laparoscopic tubectomy (groupIIIB), the patency of the fallopian tubes was found in $13(65 \%)$ of women, and in 7 (35\%) of group III C, which is less in comparison with group III B by $30 \%(p<0.05)$. The patency of fallopian tubes after laparotomy tubectomy (groupI) was $20 \%$, which is $15 \%$ less $(\mathrm{p}<0,05)$ than in the group IIIC with the previous use of cytostatics (35\%). In the case of laparoscopic access without using cytostatics (group II B), 12 (60\%) of the passable fallopian tubes, and after using methotrexate (group III C) - $13(65 \%),(p>0,05)$. Partially passable fallopian tubes were observed in $35 \%$ of womenin groupsI and III B, however it was independent of the use of methotrexate. In the group II B, the fallopian tube, that was not used, preserved partially passable in 4 women (20\%), and it was in 6 patients (30\%) in group IIIC.

There were $9(45 \%)$ women who were subsequently diagnosed with a tubal peritoneal infertility based on MSG after 
Table 2. Fallopian tubes passages in women with an ectopic pregnancy in ana mnesis based on the results of digital and analogue metrosealngography

\begin{tabular}{|c|c|c|c|c|c|c|c|}
\hline & \multirow{2}{*}{$\begin{array}{c}\text { Group I } \\
\mathbf{n}=\mathbf{2 0}\end{array}$} & \multicolumn{2}{|c|}{$\begin{array}{c}\text { Group II } \\
n=40\end{array}$} & \multicolumn{4}{|c|}{$\begin{array}{c}\text { Group III } \\
\mathbf{n}=\mathbf{8 0}\end{array}$} \\
\hline & & $\begin{array}{c}\text { II A } \\
n=20\end{array}$ & $\begin{array}{c}\text { II B } \\
n=20\end{array}$ & $\begin{array}{c}\text { III A } \\
n=20\end{array}$ & $\begin{array}{c}\text { III B } \\
n=20\end{array}$ & $\begin{array}{c}\text { III C } \\
n=20\end{array}$ & $\begin{array}{c}\text { III D } \\
n=20\end{array}$ \\
\hline Passable & $4(20 \%)$ & $11(55 \%)$ & $12(60 \%)$ & $17(85 \%)^{*}$ & $14(70 \%)^{*}$ & $13(65 \%)$ & 7 (35\%) \\
\hline $\begin{array}{l}\text { Partially } \\
\text { passable }\end{array}$ & 7 (35\%) & $4(20 \%)$ & $4(20 \%)$ & $3(15 \%)$ & $4(20 \%)$ & $6(30 \%)$ & 7 (35\%) \\
\hline Obstructed & $9(45 \%)$ & $3(15 \%)$ & $2(10 \%)$ & $0(0 \%)$ & $2(10 \%)$ & $1(5 \%)$ & $6(30 \%)$ \\
\hline
\end{tabular}

* - significant difference between the groups $(p<0,05)$

Table 3. Reproductive function of women in 2-24 months after the EP episode

\begin{tabular}{|c|c|c|c|c|c|c|c|}
\hline & \multirow[t]{2}{*}{$\begin{array}{c}\text { Group I } \\
n=20\end{array}$} & \multicolumn{2}{|c|}{$\begin{array}{c}\text { Group II } \\
n=40\end{array}$} & \multicolumn{4}{|c|}{$\begin{array}{c}\text { Group III } \\
\mathrm{n}=\mathbf{8 0}\end{array}$} \\
\hline & & $\begin{array}{c}\text { II A } \\
n=20\end{array}$ & $\begin{array}{c}\text { II B } \\
n=20\end{array}$ & $\begin{array}{c}\text { III A } \\
n=20\end{array}$ & $\begin{array}{c}\text { III B } \\
n=20\end{array}$ & $\begin{array}{c}\text { III C } \\
n=20\end{array}$ & $\begin{array}{c}\text { III D } \\
n=20\end{array}$ \\
\hline Maternal pregnancy & $2(10 \%)$ & $12(60 \%)$ & $6(30 \%)$ & $15(75 \%)$ & $14(70 \%)$ & $5(25 \%)$ & $1(5 \%)$ \\
\hline $\begin{array}{l}\text { Reproductive } \\
\text { technologies }\end{array}$ & $3(15 \%)$ & $2(10 \%)$ & $3(15 \%)$ & $1(5 \%)$ & $2(10 \%)$ & $2(10 \%)$ & $\begin{array}{c}3 \\
(15 \%)\end{array}$ \\
\hline
\end{tabular}

laparotomy tubectomy (Group I), which was the highest indicator in comparison with the whole population. In the group III C(laparotomy with tubectomy after methotrexate therapy), tubal peritoneal infertility was observed in $6(30 \%)$ of women, which is $15 \%$ lower than in the group I $(p<0,05)$. In groups II B and III B there was a decrease in the number of tubal obstruction down to $10 \%$ and $5 \%$ compared to group IIIC, respectively.

Analysis ofthe data presented in Table 3 revealed that spontaneous pregnancy occurred in 2 women (10\%) with laparotomy tubectomy (Group I) and in 1 (5\%) woman who was performed laparotomy tubectomy and previously used methotrexate (Group III C), however there was no significant difference between these groups.

Pregnancies occurred in $6(30 \%)$ women of group IIB and in $5(25 \%)$ women of group IIIB, which was $20 \%$ more than in the case of laparatomy surgery (group I). If the uterine tube is maintained, the percentage of pregnancy in the natural way was almost 2 times higher. The pregnancy occurred in $12(60 \%)$ women in the group IIA, which was 2 times higher than in the group II B and 6 times higher than in the group I. Patients of group III A showed the best result: 15 women (75\%) became pregnant independently, which is $15 \%$ higher than in the group IIA. In the group III B, when using methotrexate and laparoscopic removal of a fertilized egg with preservation of the fallopian tube, this figure was $70 \%$ (14 women), or 5\% lower than when using only methotrexate (group III A), but - 10\% higher than after conservative removal of a fertilized egg by a laparoscopic method without the use of methotrexate (group II A).16 (11.4\%) of women out of total 140 were pregnant with the help of auxiliary reproductive technologies, but differences in groups were not statistically significant, indicating the independence of this factor from the type of treatment of ectopic pregnancy in the history (Table 3).

A new ectopic pregnancy occurred in one woman of group IIA (after the conservative removal of the fetal egg) after 1.5 years. This pregnancy was localized in the opposite tube from the operated one. Two women (10\%) in the group I were readmitted with an ectopic pregnancy in a single uterine tube.

An increase in the proportion of ectopic pregnancy in the gynecological hospital was establishedon based on the conducted clinical and statistical analyses of the structure of gynecological diseases from years 2005 to 2015 .

The risk factors for developing ectopic pregnancy as follows: early sexual life (OR $=4.36$; $95 \%$ CI: $(1.50-12.69)$; $\mathrm{p}<0.05$ ), use of intrauterine helix as a contraception (OR $=6.9,95 \%$ CI: (2.07-22.00), p <0.05), abortions and inflammatory diseases of the uterus and appendages in the history $(\mathrm{OR}=2.13$; 95\% CI: $(0.63-7.16)$; $(\mathrm{p}<0.05)$.

The markers of EP diagnosis and the effectiveness of the drug treatment of this pathology are the dynamic determination of serum $\beta$-HCG levels, ultrasound examination of ectopic pregnancy with a transvaginal probe.

It has been established that significant changes have taken place in the approaches to the management and surgical treatment of ectopic pregnancy in the last decade. Thus, in 2005, the cases of laparotomy operations was $86.88 \%$, and medical treatment was only $13.16 \%$. In 2015 , the number of patients treated with methotrexate was already more than a half (51.35\%) the percentage of laparotomy operations decreased to $18.92 \%$, and the number of laparoscopic interventions with the preservation of the fallopian tube almost doubled.It was also found that restoration of menstrual function in patients receiving methotrexate was later compared to mechanically isolated ectopically placed fatal eggs. 
The use of methotrexate before surgery in patients with progressive ectopic pregnancy with high levels of $\beta-\mathrm{HCG}$ (> $1500 \mathrm{IU} / \mathrm{L}$ ) and a fetal egg of more than $3.5 \mathrm{~cm}$, followed by the conservative removal of a fertilized egg by laparoscopic access, helps to maintain the patency of fallopian tubes in $70 \%$ of cases, due to, in our opinion, medication apoptosis of trophoblast cells, separation of trophoblast from the walls of the uterine tube and thrombosis of the attachment site, that may limitmassive coagulation during surgery.

When comparing the results of the patency of the uterine tubes after the use of laparotomic access with laparoscopic access, there was a decrease in the number of tubal obstruction to $10 \%$ and $5 \%$ respectively. The effectiveness of medical treatment of ectopic pregnancy by methotrexate, which was manifested in the survival of fallopian tubes compared with surgical intervention, was established. If the uterine tube is maintained, the percentage of pregnancy in the natural way was shown to be almost twotimes higher. The best long-term outcome was shown inpatients treated with methotrexate.

\section{CONCLUSIONS}

1. Women diagnosed with progressive ectopic pregnancy should be offered conservative medical treatment that may help preserve their reproductive function in the future.

2. Treatment of women with progressive ectopic pregnancy, with an uterine tube size even more than $3.5 \mathrm{~cm}$ and unful filled reproductive plans, should include the introduction of methotrexate for 6-24 hours prior to surgery, followed by the conservative removal of the fertilized egg via a laparoscopic access. This approach was shown to maintain the patency of fallopian tubes in $70 \%$ of cases.

\section{REFERENCES}

1. Brady PC New Evidence to Guide Ectopic Pregnancy Diagnosis and Management Fellow in Reproductive Endocrinology and Infertility, Brigham and Women's Obstet Gynecol Surv. 2017 0ct;72(10):618-625. doi: 10.1097/0GX.0000000000000492.

2. Boychuk, A.; Yakymchuk, Y. Results of operative andconservative metods oftreatment ectopic pregnancies. Actual Problems of Pediatry, Obstetrics and Gynecology 2016, 2. doi:10.11603/24116-4944.2016.2.6857.

3. Boychuk A.V.; YakymchukYu.B.; Yakymchuk 0.M. Violation of homocysteine exchange in conservative treatment of ectopic pregnancy. Collection of scientific papers of the Association of Obstetriciansgynecologists of Ukraine. Polygraph plus: Kyiv, 2014, p 354. ISBN 978-966-8977-45-9.
4. Boychuk A.; Kurylo 0.U.; Tolokova T.Prevention of Adhesions in The Preservation of Reproductive Health of Women with Endometryoid Cysts.Rec. J. Pharm., Biol. Chem. Sci. 2017; 8(3): 1447-1454. ISSN: 0975-8585.

5. Cohen A.; Zakar L.; Gil, Y.; Amer-Alshiek, J.; Bibi, G.; Almog, B.; Levin, I. Methotrexate success rates in progressing ectopic pregnancies: a reappraisal. Am J Obstet Gynecol., 2014; 211(2): 128.e1-5. doi:10.1016/j. ajog.2014.03.043.

6. Tong S., Skubisz, M.M.; HorneA.W. Molecular diagnostics and therapeutics for ectopic pregnancy. Mol. Hum. Reprod. 2015; 21(2): 126-135. doi:10.1093/molehr/gau084.

7. Brady PC New Evidence to Guide Ectopic Pregnancy Diagnosis and Management. Obstet Gynecol Surv 2017;72(10):618-625. doi:10.1097/ OGX.0000000000000492.

8. Talwar, P., Sandeep, K., Naredi. N., Duggal BS Jose, T. Systemic methotrexate: An effective alternative to surgery for management of unruptured ectopic pregnancy. Med J Armed Forces India. 2013; 69 (2): 130-133. doi:10.1016/j.mjafi.2012.08.032.

9. Latchesar Tantchev, Andrey Kotzev and Angel Yordanov. Disturbed Interstitial Pregnancy: A First Case of Successful Treatment Using a Mini-Laparoscopic Approach Medicina 2019, 55, 215;doi:10.3390/ medicina55050215

\section{ORCID and contributionship:}

Alla V. Boychuk - 0000-0002-2191-0383 A,E,F

Oksana I. Khlibovska - 0000-0003-3293-0010 ${ }^{\mathrm{C}}$

Yuliia B. Yakymchuk - 0000-0002-2191-0382 B,D

\section{Conflict of interest:}

The Authors declare no conflict of interest

\section{CORRESPONDING AUTHOR \\ Alla V. Boychuk}

Department of Obstetrics and Gynecology of Postgraduate

Education, Ternopil National Medical University

Kopernika 17/3, 46001, Ternopil, Ukraine

tel: +380673025808

e-mail:boychuk_alla@tdmu.edu.ua

Received: 22.09 .2019

Accepted: 20.12.2019

A - Work concept and design, B - Data collection and analysis, C - Responsibility for statistical analysis,

D-Writing the article, $\mathbf{E}$-Critical review, $\mathbf{F}$ - Final approval of the article 